\title{
Chondrodysplasia Punctata
}

National Cancer Institute

\section{Source}

National Cancer Institute. Chondrodysplasia Punctata. NCI Thesaurus. Code C84632.

A rare congenital developmental disorder characterized by the presence of stippled foci of calcification in the hyaline cartilage, joint contractions, mental retardation and ichthyosis. 